\title{
Genotype-by-environment (temperature-humidity) interaction of milk production traits in Australian Holstein cattle
}

\author{
E. K. Cheruiyot, ${ }^{1,2}$ ๑ T. T. T. Nguyen, ${ }^{1}$ M. Haile-Mariam, ${ }^{1 *}$ ๑ B. G. Cocks,,${ }^{1,2}$ M. Abdelsayed, ${ }^{3}$ and J. E. Pryce ${ }^{1,2}$ (๑) \\ ${ }^{1}$ Agriculture Victoria Research, Department of Jobs, Precincts and Regions, Bundoora, VIC 3083, Australia \\ ${ }^{2}$ School of Applied Systems Biology, La Trobe University, Bundoora, VIC 3083, Australia \\ ${ }^{3}$ Datagene Ltd., AgriBio, Centre for AgriBioscience, Bundoora, VIC 3083, Australia
}

\begin{abstract}
Dairying in Australia is practiced in highly diverse climatic conditions and production systems, which means that re-ranking of genotypes could occur across environments that vary in temperature and humiditythat is, genotype-by-environment interactions $(\mathrm{G} \times \mathrm{E})$ may exist. The objective of this study was to investigate $\mathrm{G} \times \mathrm{E}$ for heat tolerance with respect to milk production traits in Australian Holsteins. A total of 6.7 million test-day milk yield records for first, second, and third lactations from 491,562 cows and 6,410 sires that had progeny in different climatic environments were included in the analysis. The environmental gradient used was the temperature-humidity index (THI) calculated from climate data from 163 Australian public weather stations between 2003 and 2017. Data were analyzed using univariate reaction norm (RM) sire model, and the results were compared with multitrait model (MT). The MT analysis treated test-day yields at 5 th percentile $(\mathrm{THI}=61$; i.e., thermoneutral conditions), 50 th percentile ( $\mathrm{THI}=67$; i.e., moderate heat stress conditions), and 95th percentile (THI = 73 ; i.e., high heat stress conditions) of the trajectory of THI as correlated traits. A THI series of 61,67 , and 73 , for example, is equivalent to average temperature and relative humidity of approximately $20^{\circ} \mathrm{C}$ and $45 \%, 25^{\circ} \mathrm{C}$ and $45 \%$, and $31^{\circ} \mathrm{C}$ and $50 \%$, respectively. We observed some degree of heterogeneity of additive $(\mathrm{AG})$ and permanent environmental $(\mathrm{PE})$ variance over the trajectory THI from RM analysis, with estimates decreasing at higher THI values more steeply for PE than for AG variance. The genetic correlations of the tests between the 5th and 95th percentiles of THI for milk, protein, and fat yield from RM were $0.88 \pm 0.01$ (standard error), $0.79 \pm 0.01$, and $0.86 \pm 0.01$, respec-
\end{abstract}

Received September 18, 2019.

Accepted October 30, 2019

*Corresponding author: Mekonnen.HaileMariam@agriculture.vic .gov.au tively, whereas the corresponding estimates from MT were $0.86 \pm 0.02,0.84 \pm 0.03$, and $0.87 \pm 0.03$. We observed lower genetic correlations between the 5th and 95th percentiles of THI for milk tests from recent years (i.e., 2009 and 2017) compared with earlier years (i.e., 2003 and 2008), which suggests that the level of $\mathrm{G} \times$ $\mathrm{E}$ is increasing in the studied population and should be monitored especially in anticipation of future expected increase in daily average temperature and frequency of heat events. Overall, our results indicate presence of $\mathrm{G}$ $\times \mathrm{E}$ at the upper extreme of the trajectory of THI, but the current extent of sire re-ranking may not justify providing separate genetic evaluations for different levels of heat stress. However, variations observed in the sire sensitivity to heat stress suggest that dairy herds in high heat load conditions could benefit more from using heat-tolerant or resilient sires.

Key words: genotype by environment, heat tolerance, reaction norm, multi-trait model, dairy cattle

\section{INTRODUCTION}

Concern about effects of heat stress on livestock production largely used to be an issue mainly in the tropics, but it has now expanded to temperate zones, affecting countries including Australia, Canada, the northern United States, and parts of Europe (Renaudeau et al., 2012; Polsky and von Keyserlingk, 2017). The global livestock industry has to face the double challenge of increasing production to feed a growing population, while dealing with the challenges of changing production environments (Gerber et al., 2013; Polsky and von Keyserlingk, 2017). Heat stress affects livestock production and reproduction, leading to substantial economic losses (West, 2003). Therefore, identifying appropriate genotypes to cope with changing environments is of vital importance, especially in the current scenario of global warming.

Several studies have explored the genetic basis for heat tolerance in dairy cattle and other livestock species [reviewed by Carabaño et al. (2017)]. Ravagnolo 
et al. (2000) introduced the use of climate data from weather stations in combination with test-day production data to explore the genetic components of heat stress. This approach has been preferred in many dairy studies because of the availability of large-scale climate data from public weather stations and routine milk recordings. The widely used variable for quantifying the external heat load of animals is temperaturehumidity index (THI), which is a metric combining ambient temperature and relative humidity. Ravagnolo and Misztal (2000) developed a reaction norm (RM) model, which assumes a range of heat load index delimited by a threshold value, beyond which production begins to decrease linearly with increasing THI. The RM approach is appealing because it allows environmental sensitivity (ES) of animals to be characterized based on the slope coefficient of the reaction norms (de Jong and Bijma, 2002), such that if the slope value of the RM is zero or close to zero, or if the trend of the $\mathrm{RM}$ is consistent across the environmental gradient, an animal is considered to be resilient; otherwise it is labeled "plastic" or sensitive to environmental changes (de Jong and Bijma, 2002; Berghof et al., 2019). These RM models have been widely used to evaluate genetic components of heat tolerance in dairy cattle in various countries, including the United States (Bohmanova et al., 2005; Aguilar et al., 2009), Spain (Carabaño et al., 2014), Italy (Bernabucci et al., 2014), and Germany (Hammami et al., 2015).

In Australia, Nguyen et al. (2016) applied the RM approach in Holsteins and Jersey dairy cattle, which culminated in the development and release of genomic estimated breeding values for heat tolerance to the dairy industry in 2017 (Nguyen et al., 2017; Pryce et al., 2018). The fact that dairying in Australia is practiced in a wide range of climatic conditions and production systems means that the importance of genotype-byenvironment interaction $(\mathrm{G} \times \mathrm{E})$ due to heat stress requires routine monitoring, particularly because of increased global warming. The $\mathrm{G} \times \mathrm{E}$ refers to the change in performance or change in re-ranking of animals in different environments (Falconer and MacKay Longman, 1996). If $\mathrm{G} \times \mathrm{E}$ exists, then animals are expected to re-rank in different environments, which may warrant adapting genetic evaluations for heat tolerance. Information on the extent of $\mathrm{G} \times \mathrm{E}$ for heat tolerance - that is, the performance of different genotypes across environments - such as the THI, could be useful for selection to improve thermotolerance.

Australian weather conditions vary considerably among dairying regions. Nguyen et al. (2016) provided an overview of heat stress effects in these regions. Queensland (the northeast region of the country) and
Tasmania (the southernmost region of the country) are the regions with the highest and the lowest heat load among dairying regions, with approximately 300 and approximately $100 \mathrm{~d}$ per year having THI values beyond the comfort level for dairy cattle, respectively (Nguyen et al., 2016). Also, temporal climatic profiles vary considerably, with average daily temperature in Northern Victoria, for example, ranging from -5 to $38^{\circ} \mathrm{C}$ (Nguyen et al., 2016). Climate perturbations in the form of increased temperature and frequency of heat events are expected to worsen over the next decades because of global warming (CSIRO and BoM, 2018), implying that genotype-by-climate interactions could become more relevant.

The previous study in Australia using test-day milk records from 1998 to 2001 has revealed evidence of $\mathrm{G} \times$ $\mathrm{E}$ for production traits due to heat stress in Holsteins (Hayes et al., 2003). In a later study, Haile-Mariam et al. (2008) also noted evidence of $\mathrm{G} \times \mathrm{E}$ for fertility and production traits in Australian dairy cattle. The work of Hayes et al. (2003) and Haile-Mariam et al. (2008) considered only first-lactation test-day or wholelactation records. Greater $\mathrm{G} \times \mathrm{E}$ might be expected in later lactations due to relatively greater milk yield in multiparous cows (Bernabucci et al., 2014), especially when considering a larger data set. In addition, the genetic merit for heat tolerance in Australian Holstein and Jersey cattle has been declining over the years due to selection for production traits (Nguyen et al., 2016; Nguyen et al., 2017). This implies that the extent of re-ranking across heat stress environments in these cattle populations may have increased. Furthermore, Australian dairying is predominantly pasture-based, with limited heat stress adaptation measures, unlike those, for example, in the United States, where extensive managerial and environmental strategies are used to reduce the effects of heat stress. Therefore, the Australian dairy population provides a different perspective in investigating the importance of $\mathrm{G} \times \mathrm{E}$ for heat tolerance.

The aim of this study was to investigate the magnitude of $\mathrm{G} \times \mathrm{E}$ across heat stress environments (as measured by THI) and to characterize ES in Australian Holstein cows using test-day milk yield records in combination with temperature-humidity data from public weather stations from 2003 to 2017. A secondary objective of the study was to investigate changes in $\mathrm{G} \times \mathrm{E}$ over time by comparing estimates of the genetic correlations for test-day records from different timescales. We applied RM to the data and compared the results with a multi-trait (MT) model, wherein test-day yields measured at different THI values were treated as correlated traits. 
Table 1. Overall characteristics of first-, second-, and third-parity data used in the study (SD in parentheses)

\begin{tabular}{lrrr}
\hline Item & Parity 1 & Parity 2 & Parity 3 \\
\hline Number of herds & 2,200 & 2,090 & 1,867 \\
Number of herd test dates & 99,246 & 101,492 & 87,587 \\
Number of records & $3,118,223$ & $2,195,283$ & $1,408,885$ \\
Number of cows & 491,562 & 368,953 & 243,278 \\
Number of sires & 6,410 & 6,118 & 5,622 \\
Average number of cows per herd test date & 31.42 & 21.63 & 16.08 \\
Average number of daughters per sire & 76.69 & 60.31 & $26.42(8.73)$ \\
Mean test-day milk yield (L) & $22.32(6.69)$ & $1.00(0.30)$ & $28.12(9.25)$ \\
Mean test-day fat yield (kg) & $0.84(0.25)$ & $0.86(0.27)$ & $1.07(0.33)$ \\
Mean test-day protein yield (kg) & $0.72(0.22)$ & $0.92(0.28)$ & \\
\hline
\end{tabular}

\section{MATERIALS AND METHODS}

\section{Climate Data}

The climate data included hourly dry bulb and dew point temperatures and relative humidity obtained from the Bureau of Meteorology (Melbourne, Australia) for 163 weather stations in Australia from 2003 to 2017. The locations of the weather stations and dairy herds from which the study data were obtained have been presented previously in Nguyen et al. (2016). The pairwise distances between herds and weather stations were calculated from geographical coordinates, as detailed in Nguyen et al. (2016). The 5th, 50th, and 95th percentiles of distances between weather stations were 4, 23, and $60 \mathrm{~km}$, respectively (Nguyen et al., 2016). Test-day milk records were assigned to the nearest weather station. Hourly THI for each weather station was calculated using the following formula (Yousef, 1985) and averaged for $24 \mathrm{~h}$ to obtain the daily THI:

$$
T H I=T_{d b}+\left(0.36 T_{d p}\right)+41.2,
$$

where $T_{d p}$ is dew point temperature $\left({ }^{\circ} \mathrm{C}\right)$ and $T_{d p}=$ $(237.3 \mathrm{~b}) /(1.0-\mathrm{b})$, where $\mathrm{b}=[\log (\mathrm{RH} / 100.0)+$ $\left.\left(17.27 T_{d b}\right) /\left(237.3+T_{d b}\right)\right] / 17.27$, and $\mathrm{RH}=$ relative humidity, $T_{d b}=$ dry bulb temperature $\left({ }^{\circ} \mathrm{C}\right)$. The daily THI on the test day and d 1, 2, 3, and 4 before test day were then averaged and assigned to the respective test-day records.

\section{Test-Day Data}

Milk, protein, and fat yield data were obtained from DataGene (DataGene Ltd., Melbourne, Australia). These data sets consisted of 6.6, 4.7, and 3.0 million records for first, second, and third lactations, respectively, for Holstein cows calving between 2003 and 2017. Data editing for the first lactation was as follows: (1) tests $<5$ or $>305$ DIM and test-day records with less than
10 cows were removed; (2) sires with daughters in fewer than 2 herds and herds using fewer than 2 sires were excluded; (3) only cows with at least 4 herd-test records within the first lactation were retained for analyses. Tests for the second and third lactations were then selected if the cows were present in the first lactation. The remaining data set included 11.2 million records for 823,055 cows and 6,615 sires from 3,732 herds. Due to computational limitations, roughly $60 \%$ of the data could be used for analysis. Therefore, a random sample of 2,200 herds was selected for analysis. The final data set comprised 6.7 million records for 491,562 cows and 6,410 sires (Table 1). The pedigree for this data included parents up to 15 generations.

\section{Reaction Norm Analysis}

In this study, we used RM models because they are better suited to continuous environmental descriptors (in this case, THI) and also facilitate distinguishing between individuals that are less or more affected by environmental changes. Due to computational limitations, univariate sire models were used instead of animal models. The combined data for first, second, and third lactation was fitted as follows:

$$
\begin{aligned}
& y_{i j k l m}=\mu+H T D_{i}+Y S_{j}+P A R_{k}+\sum_{n=1}^{3} A_{n} X_{n}+\sum_{n=1}^{8} P A R_{k} D_{n} Z_{n} \\
& +\sum_{n=1}^{2} P_{n} T_{n}+\sum_{n=0}^{1} S_{l n} Q_{n}+\sum_{n=0}^{1} C_{m n} W_{n}+e_{i j k l m},
\end{aligned}
$$

where $y_{i j k l m}$ is yield of milk in liters, fat or protein in $\mathrm{kg}$ from the $i$ th herd test day, jth year season of calving, lth sire, and $m$ th cow in $k$ th parity; $\mu$ is the intercept; $H T D_{i}$ is the effect of the $i$ th herd test day; $Y S_{j}$ is the effect of the $j$ th year season of calving; $P A R_{k}$ is the effect of $k$ th parity; $X_{n}$ is the $n$ th-order Legendre polynomials corresponding to age on day of test; $A_{n}$ is a fixed regression coefficient of traits on age at test; $Z_{n}$ is the 
$n$ th-order Legendre polynomials corresponding to DIM at test; $D_{n}$ is a fixed regression coefficient of traits on DIM nested within parity; $P_{n}$ is the $n$ th-order Legendre polynomial corresponding to THI; $T_{n}$ is a fixed regression coefficient of traits on THI; $S_{l n}$ is an RM coefficient on THI for the lth sire; $C_{m n}$ is the RM coefficient on THI for the $m$ th cow to account for repeated records of cows; $Q_{n}$ and $W_{n}$ are either the intercept $(\mathrm{n}=0)$ or slope solution $(\mathrm{n}=1)$ for THI for sires and cows, respectively; and $e_{i j k m}$ is the vector of residual effects. To compare our results with a previous study in Australia (Hayes et al., 2003), we also fitted the same model to first-lactation data separately, excluding the effect of parity.

Before analysis, a small proportion $(0.004 \%)$ of tests with THI values of above 75 were arbitrarily given a value of 75 . This was done to avoid possible artifacts of variance estimation using RM models, which might lead to unexpected trajectories at the extremes of the environmental descriptor due to few data points (Misztal et al., 2000). Milk yield traits in Australia begin to decline at THI > 60 (Hayes et al., 2003; Nguyen et al., 2016). Therefore, the THI threshold was set at 60 in this study (i.e., if THI $<60$, then THI $=60$ ). The variance or covariance structure for additive sire effects was the following:

$$
\operatorname{Var}(S)=\left[\begin{array}{l}
S_{0} \\
S_{1}
\end{array}\right]=\left[\begin{array}{cc}
\mathbf{A} \sigma_{S_{0}}^{2} & \mathbf{A} \sigma_{S_{0} S_{1}} \\
\mathbf{A} \sigma_{S_{0} S_{1}} & \mathbf{A} \sigma_{S_{1}}^{2}
\end{array}\right],
$$

where $\mathbf{A}$ is the relationship matrix among sires constructed from pedigree data; $S_{0}$ and $S_{1}$ are the intercept and slope for sires; and $\sigma_{S_{0}}^{2}, \sigma_{S_{0} S_{1}}, \sigma_{S_{0} S_{1}}$, and $\sigma_{S_{0}}^{2}$ are (co) variance for sire effects on environmental descriptor. The (co)variance structure for the PE effect was as follows:

$$
\operatorname{Var}(C)=\left[\begin{array}{l}
C_{0} \\
C_{1}
\end{array}\right]=\left[\begin{array}{cc}
\mathbf{I} \sigma_{C_{0}}^{2} & \mathbf{I} \sigma_{C_{0} C_{1}} \\
\mathbf{I} \sigma_{C_{0} C_{1}} & \mathbf{I} \sigma_{C_{1}}^{2}
\end{array}\right],
$$

where $\mathbf{I}$ is the identity matrix for each test-day record; $C_{0}$ and $C_{1}$ are the intercept and slope for cows; and $\sigma_{C_{0}}^{2}, \sigma_{C_{0} C_{1}}, \sigma_{C_{0} C_{1}}, \sigma_{C_{1}}^{2}$ are (co)variance for cow effects on environmental descriptor (i.e., THI).

Heterogeneous error variance was modeled for 10 DIM intervals over a lactation (DIM $=5$ to 30,31 to 60, 61 to 90,91 to 120,121 to 150,151 to 180,181 to 210, 211 to 240,241 to 270 , and 271 to 305 ), assuming the following variance structure:

$$
\operatorname{Var}(e)=\operatorname{var}\left[\begin{array}{c}
e_{1} \\
e_{2} \\
\vdots \\
e_{30}
\end{array}\right]=\left[\begin{array}{cccc}
\sigma_{e_{1}}^{2} & 0 & 0 & 0 \\
0 & \sigma_{e_{2}}^{2} & 0 & 0 \\
0 & 0 & \ddots & 0 \\
0 & 0 & 0 & \sigma_{e_{30}}^{2}
\end{array}\right] \text {, }
$$

where $\sigma_{e_{1}}^{2}, \sigma_{e_{2}}^{2}, \ldots, \sigma_{e_{30}}^{2}$ represent error variances $(30 \times 30$ error matrix for first, second, and third lactations). All analyses were performed using ASREML version 4.2 (Gilmour et al., 2015).

\section{Calculation of Genetic Parameters}

Additive genetic $16 \times 16$ (co)variance $\widehat{\mathbf{G}}$ matrixes for sires along the THI trajectory (i.e., $60 \leq \mathrm{THI} \leq 75$ ) were calculated as follows:

$$
\widehat{\mathbf{G}}=4 \times \mathbf{\Phi} \operatorname{var}(\widehat{\mathbf{S}}) \Phi^{\prime},
$$

where $\boldsymbol{\Phi}$ is the $16 \times 2$ matrix of Legendre polynomial function for THI and $\hat{\mathbf{S}}$ is a $2 \times 2$ sire (co)variance matrix. Similarly, the PE (co)variances matrix $\widehat{\mathbf{P E}}$ were calculated from $(2 \times 2) \widehat{\mathbf{C}}$ cow $($ co $)$ variance matrix. The residual (co)variance matrix $\widehat{\mathbf{R}}$ was a $16 \times 16$ identity matrix; the diagonal elements were an average of 10 estimates of variances for first parity (estimated from 10 DIM intervals over the lactation), or 30 estimates of variances for 3 parity analyses. The phenotypic (co) variance matrix $\widehat{\mathbf{P}}$ was obtained by linearly summing additive, permanent, and residual variances $(\widehat{\mathbf{P}}=\widehat{\mathbf{G}}+\widehat{\mathbf{P E}}+\widehat{\mathbf{R}})$.

The genetic correlations were calculated as $r g_{i, j}=g_{i, j} / \sqrt{g_{i, i} \times g_{j . j}}$, where $i$ and $j$ are the genetic (co) variances for yield at THI $=60$ and $\mathrm{THI} \geq 60$, respectively, and their corresponding approximate standard errors are computed as proposed by Fischer et al. (2004) and expounded in Su et al. (2007), as follows:

$$
S E^{2}=r g^{2}\left[\begin{array}{l}
\frac{\operatorname{var}\left(g_{i, i}\right)}{4\left(g_{i, i}\right)^{2}}+\frac{\operatorname{var}\left(g_{j, j}\right)}{4\left(g_{j, j}\right)^{2}}+\frac{\operatorname{var}\left(g_{i, j}\right)}{\left(g_{i, j}\right)^{2}} \\
+\frac{\operatorname{cov}\left(g_{i, i}, g_{j, j}\right)}{2 g_{i, i} g_{j, j}}-\frac{\operatorname{cov}\left(g_{i, i}, g_{i, j}\right)}{g_{i, i} g_{i, j}}-\frac{\operatorname{cov}\left(g_{j, j}, \sigma_{i, j}\right)}{g_{j, j} g_{i, j}}
\end{array}\right],
$$

where $g_{i, i}, g_{j, j}$, and $g_{i, j}$ are the elements of $(16 \times 16) \times$ $(16 \times 16) \widehat{\mathbf{G}}$ matrix with their $($ co $)$ variances $\widehat{\mathbf{V G}}$ approximated from the observed inverse of the average information matrix. 
The heritability at the ith THI was calculated as $h_{i}^{2}=\frac{4 \times g_{i, i}}{p_{i, i}}$, with their corresponding approximate standard errors computed as

$$
S E^{2}=\left(h_{i}^{2}\right)^{2}\left[4 \frac{\operatorname{var}\left(g_{i, i}\right)}{\left(g_{i, i}\right)^{2}}+\frac{\operatorname{var}\left(p_{i, i}\right)}{\left(p_{i, i}\right)^{2}}-2 \frac{\operatorname{cov}\left(g_{i, i}, p_{i, i}\right)}{4 g_{i, i} p_{i, i}}\right],
$$

where $g_{i, i}, p_{i, i}, \operatorname{var}\left(g_{i, i}\right)$, and $\operatorname{var}\left(p_{i, i}\right)$ are the diagonal elements of $\widehat{\mathbf{G}}, \widehat{\mathbf{P}}, \widehat{\mathbf{V G}}$, and $\widehat{\mathbf{V P}}$ matrices with $(16 \times 16)$ $\times \quad(16 \quad \times \quad 16) \quad$ dimensions, respectively; $\widehat{\mathbf{V P}}=\widehat{\mathbf{V G}}+\widehat{\mathbf{V P E}}+\widehat{\mathbf{V R}}$. The diagonal elements of $\widehat{\mathbf{V R}}$ were an average of 10 estimates of variances from $\widehat{\mathbf{R}}$ matrix.

The EBV along the THI trajectory for the $i$ th sire was calculated as $E B V_{i}=\emptyset_{j} \times \hat{a}_{i}{ }^{\prime}$, where $\hat{a}_{i}{ }^{\prime}$ is the vector of estimated RM coefficients for the slope and intercept for sire $i$, and $\emptyset_{j}$ is the vector of Legendre polynomials evaluated at THI $j$. To examine changes in performance, the EBV for sires with more than 100 daughters with yield records $(\mathrm{n}=617)$ were estimated and represented along the THI trajectory. Environmental sensitivity of sires was characterized according to Mattar et al. (2011), based on the absolute values of the slope of the RM: $\left|S_{i}\right|<\sigma_{s}$, resilient sires; $\sigma_{s} \leq\left|S_{i}\right| \leq 2 \sigma_{s}$, sensitive sires; and $\left|S_{i}\right| \geq 2 \sigma_{s}$, extremely sensitive sires.

\section{Multi-Trait Analysis}

To compare the results of RM, we performed an MT analysis for 3 parity data by considering tests at 5 th $(60<\mathrm{THI} \leq 61), 50$ th $(66<\mathrm{THI} \leq 67)$, and 95 th $(72$ $<$ THI $\leq 74)$ percentiles of THI distribution as different but correlated traits. Hereafter, yields at 5th, 50th, and 95th percentiles are indicated as THI $=61,67$, and 73 , respectively. The proportion of tests at the 5 th, 50th, and 95th percentile THI points were 59\% (n = $373,564), 31 \%(\mathrm{n}=192,571)$, and $10 \%(\mathrm{n}=61,548)$, respectively. A small proportion of cows $(0.007 \%, 0.008 \%$, and $0.005 \%$ ) had repeated records in at least 1 of the 3 THI percentiles for parity 1,2 , or 3 , respectively. An initial model considering PE effects, aimed at accounting for the repeated records, failed to converge, most likely due to a few repeated data. Therefore, only 1 record was randomly selected at each THI point for all the cows with repeated records and included in the final analysis.

The following MT model was fitted to the data:

$$
\begin{aligned}
& y_{t i j k l}=\mu+H T D_{t i}+Y S_{t j}+P A R_{t k}+\sum_{n=1}^{3} A_{t n} X_{t n} \\
& +\sum_{n=1}^{8} P A R_{t k} D_{t n} Z_{t n}+S_{t l}+e_{t i j k l},
\end{aligned}
$$

where $y_{t i j k l}$ is the $n$th observation for the th trait (i.e., yields at 5th, 50th, and 95th THI percentiles); $\mu_{t}$ is the overall mean for the th trait. Fixed effects were the same as described in the RM model, except that the fixed regression of the environment descriptor (THI) was excluded; and $S_{t l}$ is the random effect of the $l$ th sire for the th trait. The (co)variance structure for the 3 traits was as follows:

$$
\operatorname{var}\left[\begin{array}{c}
S_{1} \\
S_{2} \\
S_{3} \\
e_{1} \\
e_{2} \\
e_{3}
\end{array}\right]=\left[\begin{array}{cccccc}
\mathbf{A} \sigma_{S_{1}}^{2} & \mathbf{A} \sigma_{S_{1} S_{2}} & \mathbf{A} \sigma_{S_{1} S_{3}} & 0 & 0 & 0 \\
\mathbf{A} \sigma_{S_{2} S_{1}} & \mathbf{A} \sigma_{S_{2}}^{2} & \mathbf{A} \sigma_{S_{2} S_{3}} & 0 & 0 & 0 \\
\mathbf{A} \sigma_{S_{3} S_{1}} & \mathbf{A} \sigma_{S_{3} S_{2}} & \mathbf{A} \sigma_{S_{3}}^{2} & 0 & 0 & 0 \\
0 & 0 & 0 & \sigma_{e_{1}}^{2} & 0 & 0 \\
0 & 0 & 0 & 0 & \sigma_{e_{2}}^{2} & 0 \\
0 & 0 & 0 & 0 & 0 & \sigma_{e_{3}}^{2}
\end{array}\right],
$$

where $S_{1}, S_{2}$, and $S_{3}$ are the genetic sire effects for the cows with records in the 5 th, 50th, and 95th percentiles of THI distribution, respectively; $\mathbf{A}$ is the relationship matrix for sires constructed from pedigree; $\sigma_{S_{1}}^{2}, \sigma_{S_{2}}^{2}, \sigma_{S_{3}}^{2}, \sigma_{S_{1} S_{2}}, \sigma_{S_{1} S_{3}}, \sigma_{S_{2} S_{1}}, \sigma_{S_{2} S_{3}}$, and $\sigma_{S_{3} S_{1}}$ are the sire genetic (co)variances for the milk records at the 3 THI percentiles; and $\sigma_{e_{1}}^{2}, \sigma_{e_{2}}^{2}$, and $\sigma_{e_{3}}^{2}$ are the residual variances for the 3 traits.

\section{Changes in Genetic Correlations over Time}

To see whether $\mathrm{G} \times \mathrm{E}$ has changed over time, we divided data from first-parity test-day yields into 2 groups: (1) tests from 2003 to 2008 and (2) tests from 2009 to 2017. We then compared the sizes of genetic correlations in these subsets. The 2 timescales were arbitrarily chosen to ensure that the number of records in each subset was similar. Unlike the RM above, all the first-parity data that remained after editing were included, to ensure sufficient records in each subset. Only first-lactation data were used to minimize possible bias of selection and to be comparable to previous work in Australia (Hayes et al., 2003). Subset 1 (2003 to 2008) comprised 2.8 million records of 444,818 cows and 4,225 sires, whereas subset 2 (2009 to 2017) com- 
prised 2.7 million records of 427,800 cows and 4,668 sires. The same RM, as described earlier, was applied to each subset separately, excluding the effect of parity.

\section{RESULTS}

\section{Climate Data and Phenotypes}

The distribution of THI is presented in Figure 1. Approximately $45 \%$ of the milk records in this study had a THI of greater than 60 , which is the threshold determined as being indicative of heat stress (Hayes et al., 2003; Nguyen et al., 2016). The average test-day yields increased from the first to the third lactation for all milk traits (Table 1). The average yields for multi-parity data used in the MT analysis are relatively greater at the 95th percentile of THI (Table 2), but with larger standard deviations.

\section{Additive Genetic and Permanent Environmental Variances}

Sire parameter estimates resulting from the $\mathrm{RM}$ model are given in Table 3. As expected, the correlations between the intercept and the slope of the reaction norms were negative for all traits: milk $(-0.10)$, protein
$(-0.05)$, and fat $(-0.26)$. Additive genetic (AG) variance along the trajectory of THI for milk, protein, and fat yields from RM and MT are presented in Figure 2. The estimates for AG variance were higher for the MT than for the RM analysis for all the milk traits, particularly at higher THI values (i.e., 95th percentile; Figure 2). The estimates and trends for the AG variance across the THI are similar for both analyses. In RM, the AG variance for milk and protein yield decreased with increasing THI values up to approximately THI = 70 , beyond which it increases slightly. For fat yield, the AG variance increased marginally at THI $>72$. The estimates for AG variance ranged from 3.06 to 3.65 $\left(\mathrm{L}^{2}\right), 0.002$ to $0.003\left(\mathrm{~kg}^{2}\right)$, and 0.003 to $0.004\left(\mathrm{~kg}^{2}\right)$ for milk, protein, and fat, respectively. In MT, estimates decreased from the 5 th $(\mathrm{THI}=61)$ to the 50 th percentile $(\mathrm{THI}=67)$ and appear to markedly increase at the 95th percentile, with conspicuously larger standard errors at the 95th compared with those for the 5th and 50 th percentiles. The estimates of AG variance from MT models are given in Table 2.

The patterns of permanent environmental $(\mathbf{P E})$ variances for milk traits from RM (Figure 2) are similar to the pattern of AG variance, with estimates decreasing with increasing THI, up to around THI $=70$, beyond which it increases. The PE component was consider-

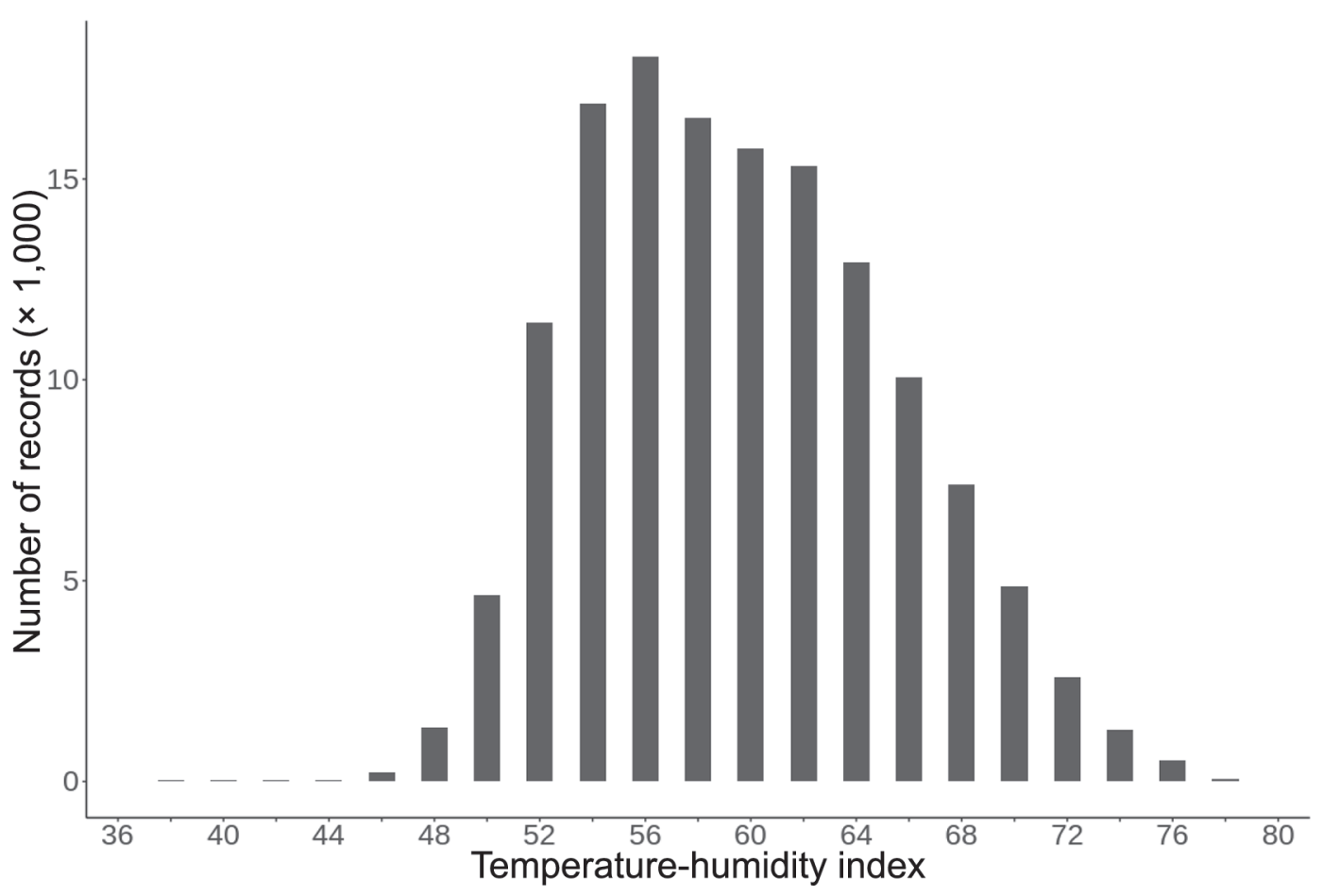

Figure 1. Distribution of temperature-humidity index (THI) values in the data used in this study: THI $<60,55 \%$; $60 \leq$ THI $\leq 65,26 \%$; $65<\mathrm{THI} \leq 70,14 \%$; and $\mathrm{THI}>70,5 \%$. 


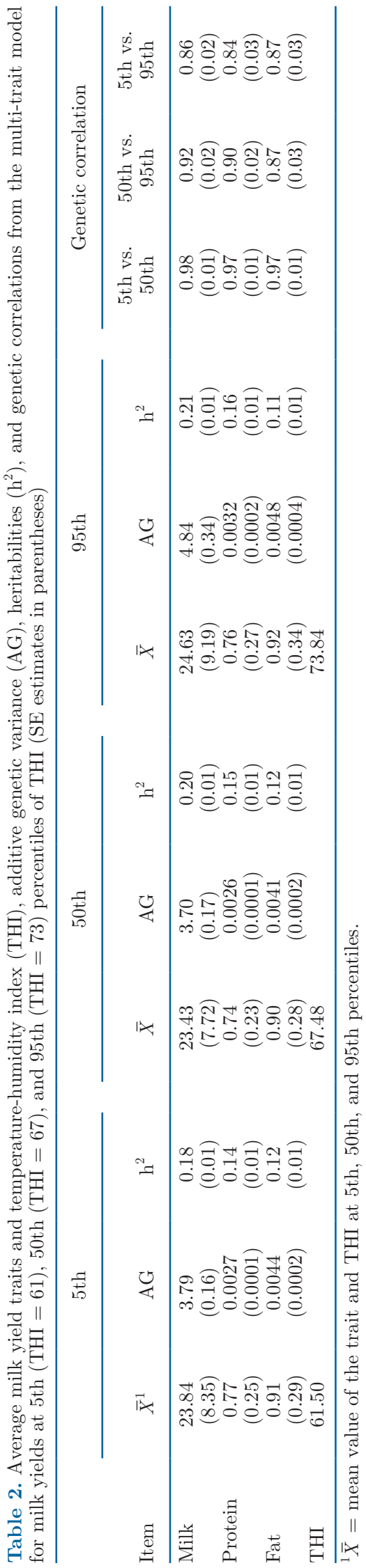

ably higher than the AG variance component, with estimates that were more than 2-fold higher, particularly at lower THI values. For example, at the 5th percentile $(\mathrm{THI}=61)$, the estimated $\mathrm{PE}$ variance for milk yield was $8.38\left(\mathrm{~L}^{2}\right)$, whereas the AG variance was $3.59\left(\mathrm{~L}^{2}\right)$. The changes in estimated PE variance along the THI trajectory were greatest for protein (34\%), followed by fat $(25 \%)$ and milk yield $(23 \%)$, relative to estimates from RM analysis between $\mathrm{THI}=61$ and $\mathrm{THI}=70$ (i.e., the interval between which estimates decrease). The PE estimates ranged from 6.60 to $8.58\left(\mathrm{~L}^{2}\right), 0.005$ to $0.007\left(\mathrm{~kg}^{2}\right)$, and 0.008 to $0.011\left(\mathrm{~kg}^{2}\right)$ for milk, protein, and fat yield, respectively; note that the PE variance was not fitted in MT analysis.

\section{Heritabilities}

Heritability estimates along the THI trajectory from RM and MT analyses are presented in Figure 3. For both analyses, heritability estimates are highest for milk followed by protein and fat yields, respectively. In RM, heritability estimates decrease with increasing THI across the entire trajectory of fat, but it increases at THI $>70$ for milk and protein yield, with a more pronounced increase for protein relative to milk yield. The steeper line curve for fat yield indicates larger decreasing estimates. The heritability estimates for milk, protein, and fat yield over THI trajectory (i.e., $60 \leq$ $\mathrm{THI} \geq 75)$ ranged from $0.13 \pm 0.01$ to $0.14 \pm 0.009$, $0.10 \pm 0.007$ to $0.11 \pm 0.01$, and $0.07 \pm 0.007$ to 0.09 \pm 0.006 , respectively. The standard errors for these estimates (Figure 3) are consistent across the THI trajectory, with a slight increase at the extremes. When considering only first-parity data in RM analysis, heritability estimates increased marginally for milk $(0.14$ \pm 0.01 to $0.16 \pm 0.01)$, protein $(0.10 \pm 0.01$ to $0.12 \pm$ $0.01)$, and fat $(0.08 \pm 0.01$ to $0.11 \pm 0.01)$.

In contrast, heritability estimates from MT were greater than those from RM, with values at 5th and 95th percentiles of $0.18 \pm 0.007$ and $0.21 \pm 0.01,0.14$ \pm 0.006 and $0.16 \pm 0.01$, and $0.11 \pm 0.01$ and 0.12 \pm 0.006 for milk, protein, and fat yields, respectively (Table 2). Unlike RM, the estimates for all the milk traits from MT at higher THI (i.e., 95th) are associated with large standard errors (Figure 3).

\section{Genetic Correlations}

The genetic correlation estimates for milk production traits between THI $=60$ and those beyond THI $=60$ are similar for both RM and MT analyses, with slightly larger estimates for protein and fat yields from MT at higher THI values (Figure 4). The genetic correlations between tests at $\mathrm{THI}=60$ versus $\mathrm{THI}>$ 
Table 3. Sire variance estimates of intercept $\left(\sigma_{S_{0}}^{2}\right)$ and slope $\left(\sigma_{S_{1}}^{2}\right)$, covariance between slope and intercept $\left(\sigma_{s_{0} s_{1}}\right)$, correlation between slope and intercept $\left(r_{s_{0} s_{1}}\right)$, residual variance $\left(\sigma_{e}^{2}\right)$, and heritability of intercept $\left(h_{S_{0}}^{2}\right)$ and slope $\left(h_{S_{1}}^{2}\right)$ from reaction norm analysis for multi-parity data for milk, protein, and fat yields (SE in parentheses)

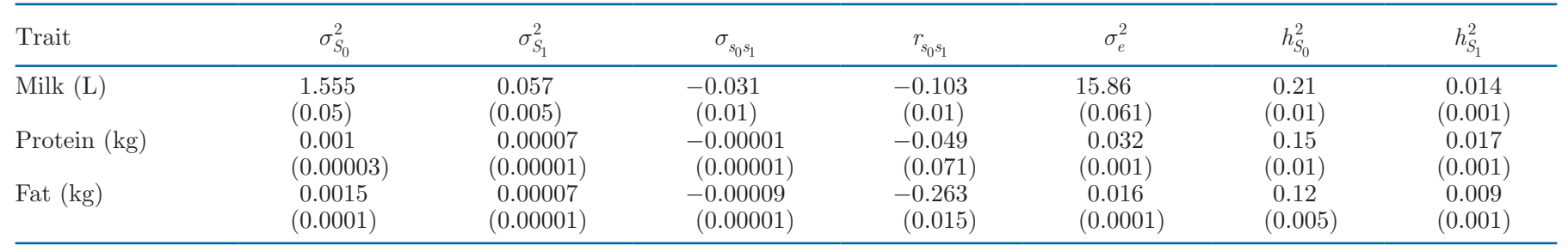

70 were lowest for protein, followed by milk and fat yields, respectively. The correlation estimates for tests between the 5 th and the 95th percentiles of THI from $\mathrm{RM}$ were $0.88 \pm 0.01,0.79 \pm 0.02$, and $0.86 \pm 0.02$ for milk, protein, and fat yield. These were in good general agreement with estimates from MT, which were $0.86 \pm$ $0.02,0.84 \pm 0.03$, and $0.87 \pm 0.03$, respectively (Table 2 and Figure 4).
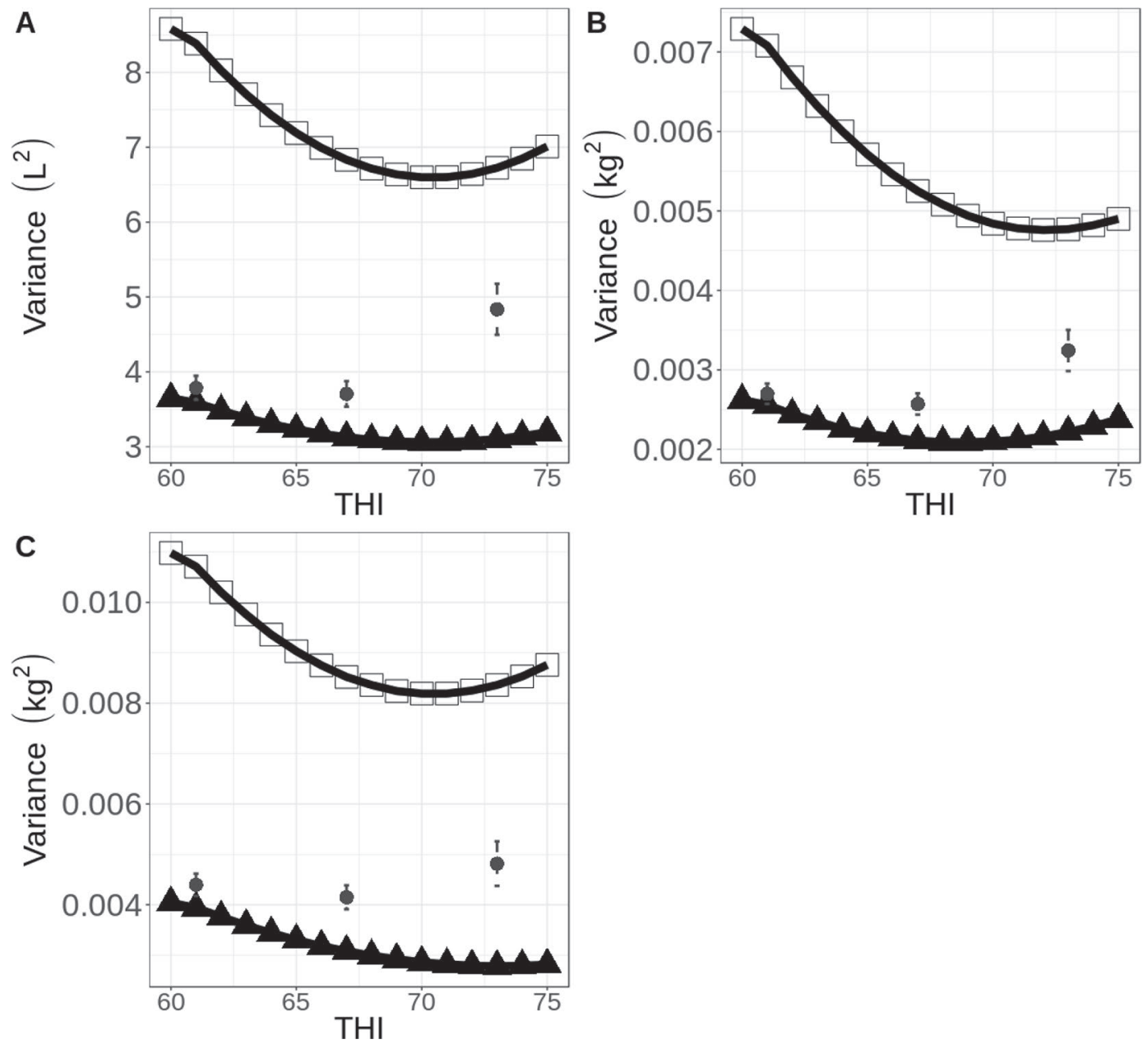

Figure 2. Additive genetic $(\boldsymbol{\Lambda})$ and permanent environmental $(\square)$ variance along the trajectory of the temperature-humidity index (THI) for milk (A), protein (B), and fat (C) yields from reaction norm analysis. Dot points $(\bullet)$ represent additive genetic variances and respective SE (vertical dashed lines) at 5 th $(\mathrm{THI}=61), 50 \mathrm{th}(\mathrm{THI}=67)$, and 95th $(\mathrm{THI}=73)$ THI percentiles from the multi-trait analysis. 


\section{Changes in Correlations over Time}

The genetic correlations from RM for the data split into 2 subsets are shown in Figure 5. Subset 1 were test-day records from 2003 to 2008, and subset 2 were test-day records from 2009 to 2017. The correlation estimates are comparatively lower for more recent data (subset 2) than for older data (subset 1) at extreme THI values for all the milk traits, with the largest differences observed for protein, followed by fat and milk yields (Figure 5). The correlation estimates for milk, protein, and fat yields between the 5th and 95th THI points for subset 1 (2003 to 2008) were $0.89 \pm 0.01$, $0.84 \pm 0.02$, and $0.86 \pm 0.02$; whereas those for subset 2 (2009 to 2017) were $0.87 \pm 0.01,0.79 \pm 0.02$, and 0.81 \pm 0.02 , respectively.

\section{Quantifying Resilience to Heat Stress}

Figure 6 shows the EBV (i.e., the slope of the reaction norms) over the trajectory of THI for a random sample of 10 sires with more than 100 daughters with records. The reaction norms are very similar for all milk traits. Two groups of sires can be identified based on the magnitude of their EBV at thermoneutral conditions (THI $=60)$ versus heat stress conditions $(\mathrm{THI}=75)$. The first group (shown in gray) are sires with above-average $\mathrm{EBV}$ at $\mathrm{THI}=60$ and smaller $\mathrm{EBV}$ at $\mathrm{THI}=75$. The second group (black) are sires with above-average EBV at $\mathrm{THI}=60$ and stable EBV (i.e., their EBV do not substantially change at $\mathrm{THI}=60$ and $\mathrm{THI}=75)$.

The correlation between EBV for slope and intercept of the reaction norms for milk, protein, and fat yield were $-0.20,-0.39$, and -0.25 , respectively. The slope of the reaction norms (i.e., ES) for sires with at least 100 daughters with records in multi-parity ranged from -11.69 to $5.84(\mathrm{SD}=2.08),-3.19$ to $1.96(\mathrm{SD}=0.82)$, and -2.92 to $2.29(\mathrm{SD}=0.75)$ for milk, protein, and fat yields, respectively. Of these, the percentage of resilient sires (i.e., sires with EBV with consistent slope) were $65 \%, 57 \%$, and 64\%, respectively (Figure 7). Greater proportions of sensitive sires were found for more recent milk tests (2009 to 2017) than for earlier tests (2003 to 2008) particularly for milk (30 vs. $23 \%$ ) and protein yield (29 vs. $26 \%$ ) (Figure 8 ).

\section{DISCUSSION}

In this study we used test-day milk production records from across Australia to estimate $\mathrm{G} \times \mathrm{E}$ for heat tolerance - that is, the changes in the relative performance of different genotypes (sires) across THI environments (i.e., heat stress conditions). Australia is a large country, with dairy herds dispersed throughout the country and in 8 distinct dairying regions (Dairy Australia, 2016). Quantifying the extent of re-ranking due to heat stress in Australian dairy cows is important for 2 main reasons. First, Australia's dairy herds are kept in highly diverse climatic conditions, ranging from the warmer northeast regions to the cooler southeast regions of the country. As such, dairy cows experience varying magnitudes of heat stress (both temporal and seasonal), with some dairying regions, including Queensland, New South Wales, and Western and South Australia, under relatively high heat loads extending up to half of the year, whereas temperatures are moderate in Victoria and lowest in Tasmania, the southernmost part of the country (Nguyen et al., 2016). Second, Australian dairy farms are mostly kept outdoors and follow pasture-based systems, with limited management measures to alleviate heat stress, in contrast to many European countries, the United States, and Canada, where cows are generally housed indoors and fed TMR. Thus, Australia is likely to be a good case study for examining $\mathrm{G} \times \mathrm{E}$ due to heat stress in dairy cows.

\section{Variance Components}

$A G$ Variance. In our analyses, we used RM in addition to the MT model for comparison purposes. We found similar estimates for AG variance from both approaches at lower THI values, but differences between estimates increased at higher levels of THI (i.e., 95th percentile). The contradictory results at extreme trajectories were expected because of the sparsity of data, which perhaps led to poor fitting in both analyses. The general trend of AG variance was similar in both analyses and consistent with other studies that reported a typical U-shaped variance pattern for production traits due to heat stress (Ravagnolo et al., 2000; Aguilar et al., 2009; Brügemann et al., 2011). The AG variance for all the milk traits from RM was relatively stable across the THI trajectory (Figure 2), suggesting that a similar response to selection is expected regardless of the THI environment.

$P E$ Variance. As with the AG variance, we also observed a declining trend for PE variance for all the milk traits across THI environment, which is in line with those reported for protein yields in German Holsteins (Brügemann et al., 2011) and milk yields in Iranian Holstein cattle (Santana Jr. et al., 2015). The higher $\mathrm{PE}$ estimates than AG variance from RM is consistent with other studies (Aguilar et al., 2009; Brügemann et al., 2011), indicating a greater effect of heat stress on production traits. 
We used the first-order polynomial function to model changes in PE as well as AG variance across THI trajectory in RM analysis. Applying higher-order regression, such as quadratic regression, might have allowed a better fit to the data (Strabel et al., 2005), but this was computationally impractical due to the large data size used in this study. Nonetheless, similar studies in Australia (Hayes et al., 2003; Nguyen et al., 2016) have successfully applied first-order polynomial functions to evaluate heat tolerance for production traits in Holsteins and Jersey dairy cattle.

Heritabilities. We used the average value of heterogeneous variances over the DIM to estimate heritability in RM, whereas separate residual variances for the 3 "traits" (i.e., yields at 5th, 50th, and 75th THI percentiles) were used in MT. We found contradicting trends for heritability estimates across the THI trajectory from the 2 analyses, which may be attributable, at least in part, to the way the heritability estimates were calculated. An alternative to RM, which perhaps could have allowed more comparable results, would have been to model (co)variance components for the interactions between DIM and THI, as in Bohlouli et al. (2019), and then estimate residual variances and heritabilities within DIM $\times$ THI combinations, but unfortunately this was not computationally feasible in our study.

Our heritability estimates from RM for both firstparity and multi-parity data were almost 2-fold lower than those reported in a previous study in Australia (Hayes et al., 2003). In that work, the authors applied the same RM as in our study and found estimates for first-parity milk, protein, and fat yields at 5th and 95th
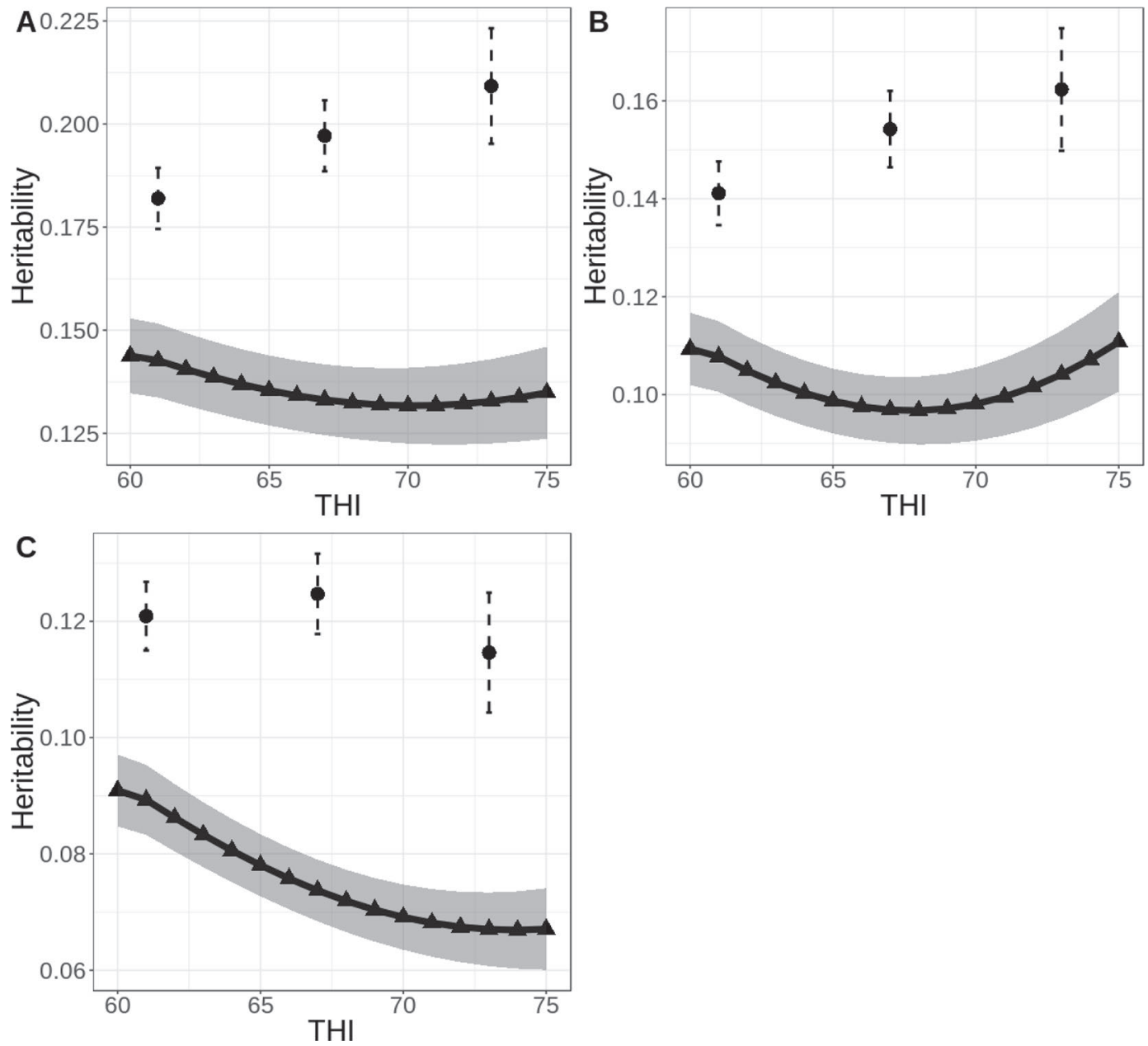

Figure 3. Heritabilities for milk (A), protein (B), and fat (C) yields across the temperature-humidity index (THI) obtained from the reaction norm (RM) and multi-trait (MT) analyses. Lines represent estimates obtained from RM and their approximate SE (shaded area). Dot points $(\bullet)$ are estimates and their SE (dashed vertical lines) at 5th $(\mathrm{THI}=61)$, 50th $(\mathrm{THI}=67)$, and 95th $(\mathrm{THI}=73)$ percentiles from the MT. 
THI percentiles of 0.26 and $0.24,0.21$ and 0.19 , and 0.19 and 0.16 , respectively. Although our estimates from MT were greater than those from RM, they are still much lower than those found by Hayes et al. (2003). Moreover, our estimates are lower than the heritability estimates for heat tolerance for first-lactation Australian Holsteins reported by Nguyen et al. (2016) for milk (0.19), protein (0.17), and fat (0.17) yields, which used a genomic relationship matrix to derive heritabilities. A relatively wide range of heritability estimates from 0.10 to 0.35 (Carabaño et al., 2014), 0.14 to 0.31 (Bohlouli et al., 2013), and 0.10 to 0.24 (Aguilar et al., 2009) contrasts with the narrow range for all the milk traits observed here, which can be attributed in part to the narrow range of the available THI scale (i.e., THI $=60$ to THI $=75)$ as well as to the small change in genetic variance observed across the trajectory of THI.
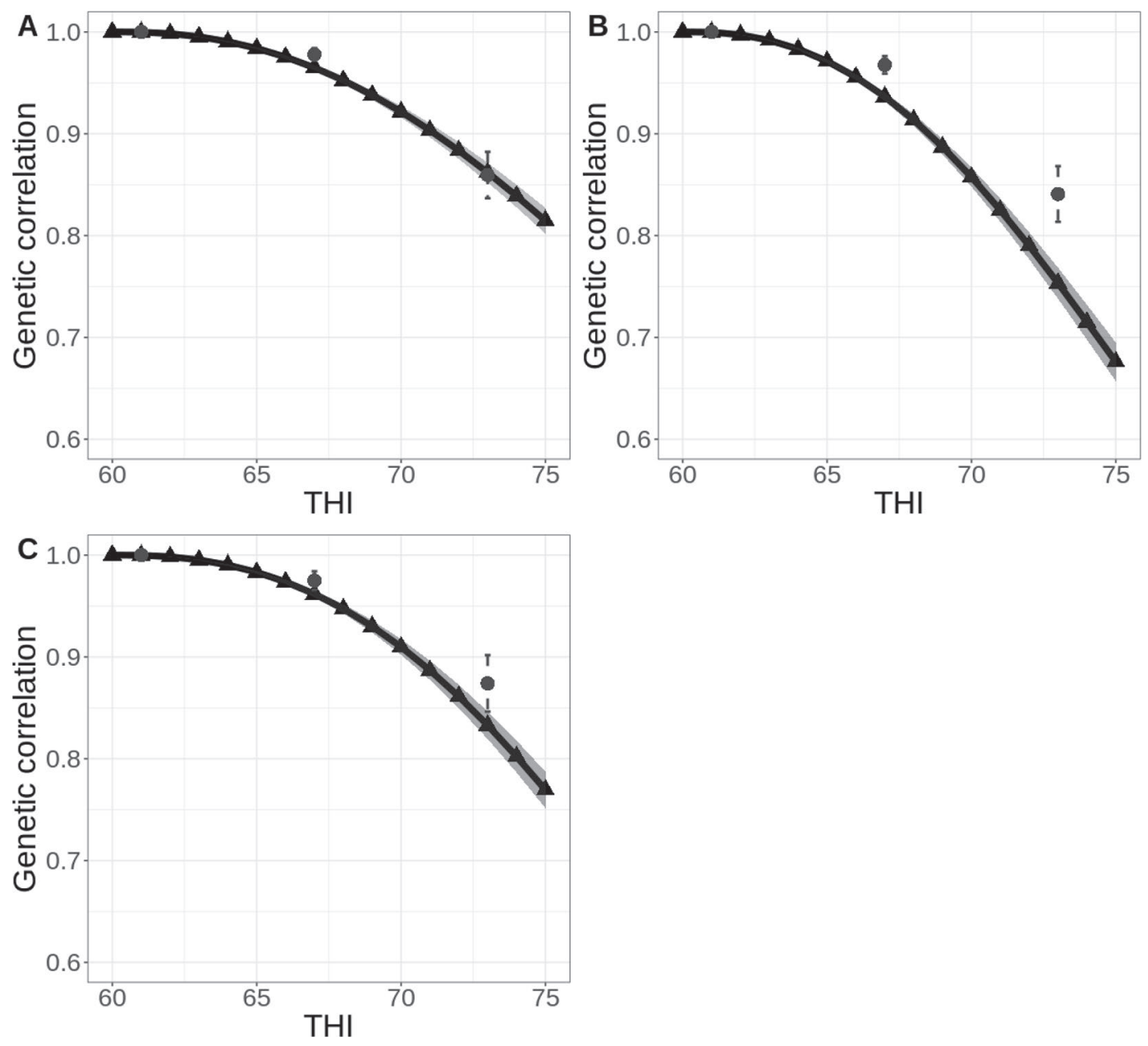

\section{Genetic Correlations and Changes over Time}

The correlation estimates of yield traits at 5 th versus 95th THI percentiles from both RM and MT analyses were 0.80 or more but are lower than those reported by Hayes et al. (2003), which considered only first-parity data. The correlations between the 5th and the 95th percentiles reported by Hayes et al. (2003) for milk, protein, and fat yield were $0.94,0.92$, and 0.90 , respectively. Our results confirm previous work in Australia (Hayes et al., 2003; Haile-Mariam et al., 2008), which found that $\mathrm{G} \times \mathrm{E}$ exists at extreme THI values (i.e., THI > 70) for milk traits, but we observed greater G $\times \mathrm{E}$ in the study population. In addition, we observed the greatest $\mathrm{G} \times \mathrm{E}$ for protein yield, whereas Hayes et al. (2003) found that fat yield had the greatest $G$ $\times$ E. When considering only first-parity data in our 
RM analysis, as in Hayes et al. (2003), the correlations changed slightly with estimates for the 5 th versus the 95th percentile of 0.89 (milk), 0.84 (protein), and 0.85 (fat), which further confirms greater $\mathrm{G} \times \mathrm{E}$ in the data used in our study. Later-parity cows appear to be more susceptible to heat stress than first-parity cows (Aguilar et al., 2009; Bernabucci et al., 2014), and greater $\mathrm{G} \times \mathrm{E}$ was expected when analyzing data sets that include multiple lactations in our study.

Despite large variability in climatic differences in Australia, most dairying is concentrated in the state of Victoria, which typically experiences moderate heat loads; around two-thirds of the Australian national dairy herd data comes from this state (DataGene, 2016; Nguyen et al., 2016). For example, of the total national herd statistics for 2015 to 2016, the number of herds in Victoria were 1,756 (approx. $65 \%$ of the national herd data records for 2015 to 2016), as opposed to 183 (approx. 7\%) from Queensland (DataGene, 2016). This is reflected in our study, in which the milk tests obtained under high heat loads (i.e., THI > 70) accounted for approximately $10 \%$ of the total records, which means that the effect of the upper extreme of the THI trajectory in proportion to the total data is small.

However, our results demonstrate that $\mathrm{G} \times \mathrm{E}$ due to heat stress in Australia dairy cows is becoming more important. This is evidenced by the decrease in the genetic correlations among milk traits over time, with greater decreases for protein $(0.84 \pm 0.016$ vs. $0.79 \pm$ $0.02)$ and fat $(0.86 \pm 0.02$ vs. $0.81 \pm 0.02)$ than for milk yield $(0.89 \pm 0.01$ vs. $0.87 \pm 0.01)$. The increasing $G$ $\times \mathrm{E}$ in this study could be associated, at least in part, to the greater sensitivity to heat stress in the study population. Nguyen et al. (2017) noted that the genetic
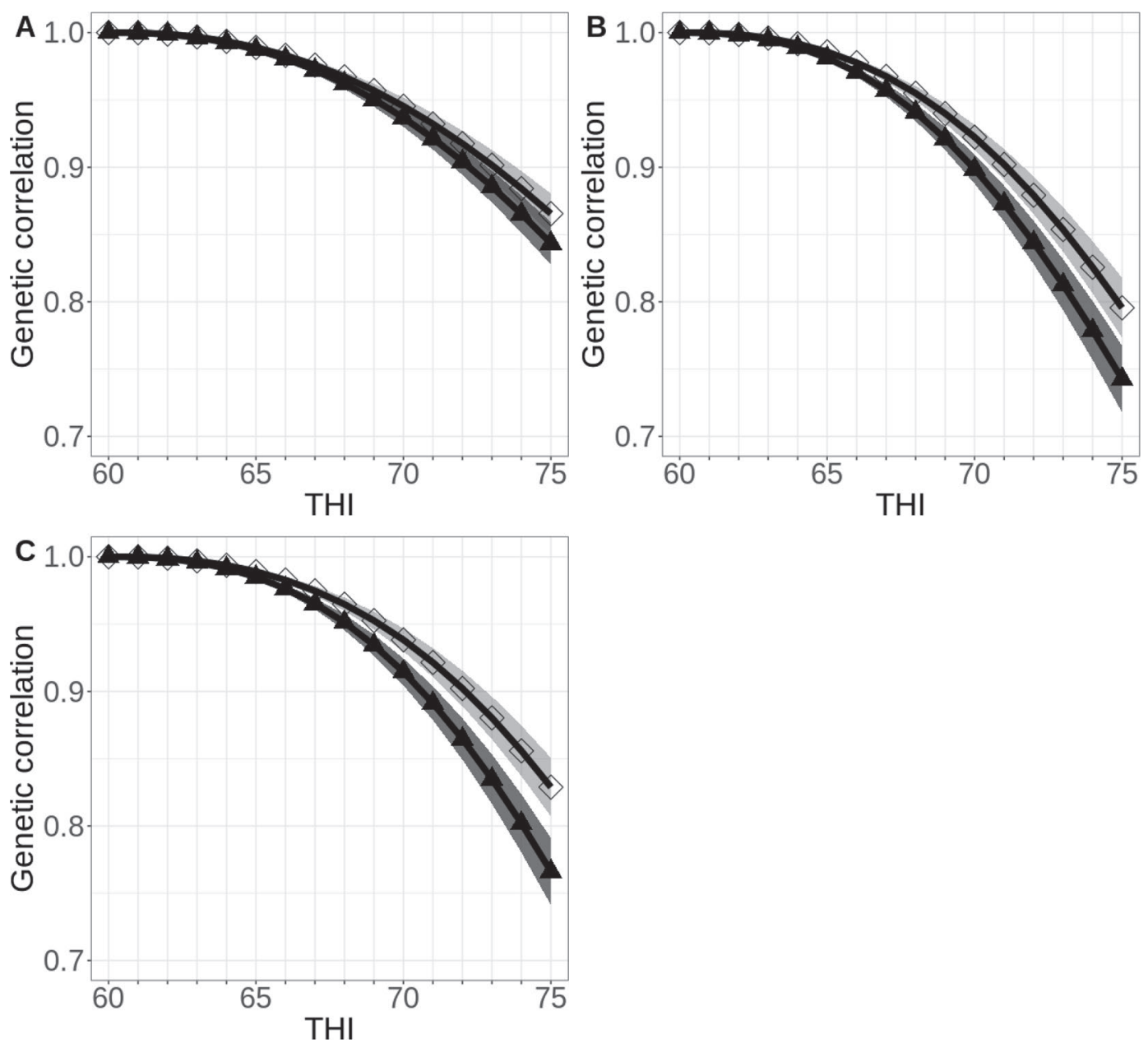

Figure 5. Genetic correlations from reaction norm analysis for milk (A), protein (B), and fat (C) yields from 2003 to 2008 ( $\square$ ) and from 2009 to $2017(\mathbf{\Delta})$. Lines represent genetic correlations for milk traits between temperature-humidity index (THI) at 60 and all THI $\geq 60$. Shaded areas are approximate SE. 
merit for heat tolerance has been declining over the years at a rate of $0.3 \% / \mathrm{yr}$ in Australian Holstein and Jersey cattle due to continued selection for production traits. Therefore, routine monitoring of $\mathrm{G} \times \mathrm{E}$ is highly recommended, given that climatic perturbations in Australia in terms of increased intensity and frequency of heat events are anticipated to worsen in the next decades (CSIRO and BoM, 2018).

\section{Quantifying Resilience to Heat Stress}

Resilient animals are minimally affected by environmental disturbances (Colditz and Hine, 2016; Berghof et al., 2019), and their performances are expected to be comparatively consistent under different heat stress conditions. Our results suggest that the proportion of resilient sires has decreased in recent years (Figure 8), confirming the increasing relevance of $\mathrm{G} \times \mathrm{E}$ in the study population. For example, the proportion of resilient sires in milk yield tests from 2003 to 2008 was $69 \%$, versus $63 \%$ for tests between 2009 and 2017. As noted previously, the increasing $\mathrm{G} \times \mathrm{E}$ could be partly associated with the decline in genetic merit for heat tolerance over the years, resulting from more emphasis on production traits in the breeding goals (Nguyen et al., 2016, 2017). In contrast to resilient sires, the performance of the daughters of sensitive sires fluctuates, and they are likely to produce less under heat stress conditions and may be best suited for milk production in regions with consistently low heat loads. If they are to perform optimally and consistently under high heat load conditions, then a more controlled environment is necessary, such as the provision of shade and diets designed to lower core body temperature.
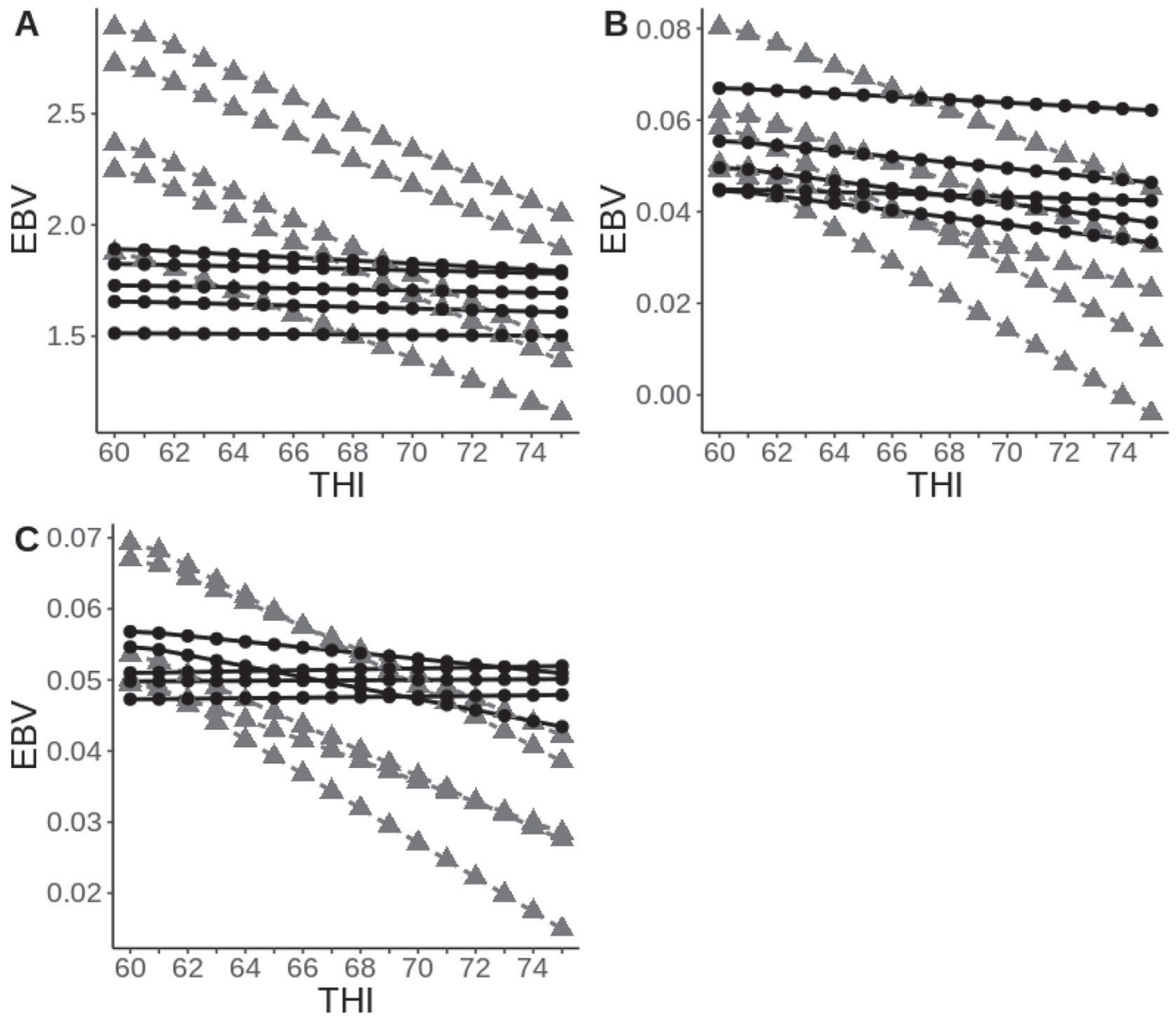

Figure 6. Estimated breeding values (i.e., the slope of reaction norms) for milk (A), protein (B), and fat (C) yields over the temperaturehumidity index (THI) for a sample of 10 sires with over 100 daughters with yield records. Gray lines $(\mathbf{\Lambda})$ represent sires with above-average EBV at thermoneutral conditions $(\mathrm{THI}=60)$ and smaller EBV at heat stress conditions $(\mathrm{THI}=75)$, whereas black lines $(\bullet)$ are sires with aboveaverage and stable EBV (i.e., their EBV do not substantially change at THI $=60$ and $\mathrm{THI}=75$ ). 


\section{Implications}

Genomic estimated breeding values for heat tolerance were released to the Australian dairy industry in 2017 for selection of animals that are more tolerant to heat stress (Nguyen et al., 2017; Pryce et al., 2018). Our results (genetic correlations $\geq 0.80$ ) indicate that optimal genetic gain for heat tolerance can be achieved with the current genetic evaluations. Although these results do not justify separate breeding programs, reranking can still occur among some sires because of the heterogeneity of genetic variance and heritabilities observed across heat loads (Figures 2 and 3). Moreover, the differences in the patterns of reaction norms (i.e., the slope of EBV) for some sires (Figure 6) suggest that some farmers should be aware that re-ranking may occur, especially in regions such as Northern Victoria and Queensland, which experience broad ranges of weather conditions, with average daily temperature up to $38^{\circ} \mathrm{C}$ (Nguyen et al., 2016). It may be more beneficial to use resilient sires in such regions. Several approaches are available to incorporate $\mathrm{G} \times \mathrm{E}$ into the genetic evaluation provided to the dairy industry. For example,
Kolmodin et al. (2002) proposed a unique ranking of sires according to the environment in which they will perform, so that farmers can choose bulls that best fit their production environments. Similarly, Bryant et al. (2006) suggested the development of customized EBV for specific environments, and (Nguyen et al., 2017) proposed a selection tool that could balance the profit index and heat tolerance. More recently, some authors have demonstrated opportunities for including resilience in breeding goals (Mulder, 2016; Friggens et al., 2017; Berghof et al., 2019). Berghof et al. (2019) proposed using the slope of the reaction norms as an indicator trait for resilience to heat stress and calculating economic values for selection index based on the reduced labor costs associated with the management of heat-stressed animals. Our study shows the existence of genetic variation in sire sensitivity to heat stress, which could be exploited in the selection of resilient animals or to optimize breeding programs for different environments. Currently, economic drivers in the Australian national selection index (Balanced Performance Index; BPI) favors production traits, which account for about $50 \%$ of the selection pressure, and does not include

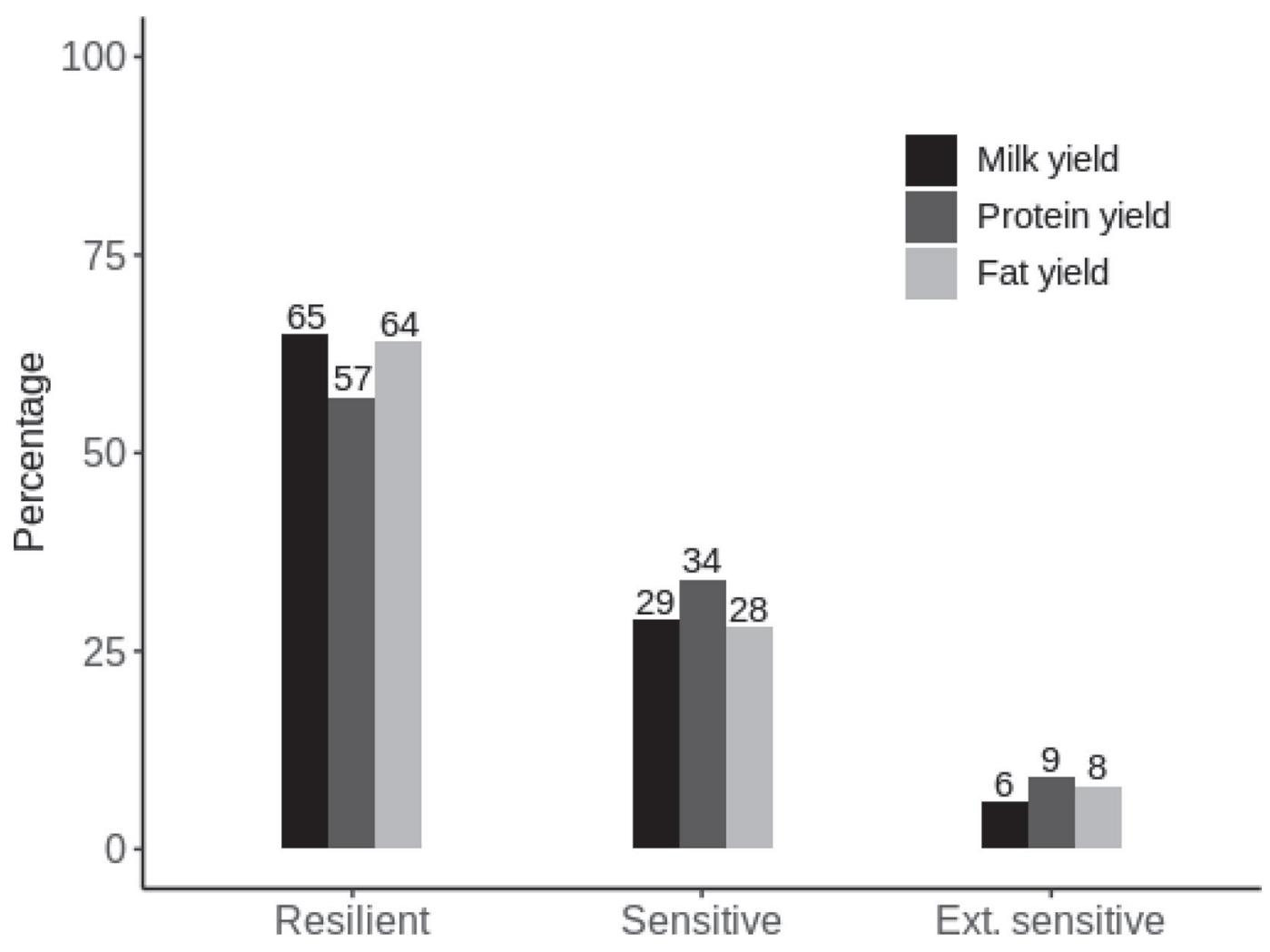

Figure 7. Proportion of resilient, heat sensitive, and extremely (ext.) sensitive sires for milk, protein, and fat yields, grouped based on the absolute values of the slope $(S)$ of the reaction norms, from analysis of whole data set: $\left|S_{i}\right|<\sigma_{S}$, resilient sires; $\sigma_{S} \leq\left|S_{i}\right|<2 \sigma_{S}$, sensitive sires; and $\left|S_{i}\right| \geq 2 \sigma_{S}$, extremely sensitive sires. Values on the tops of the bars are actual percentages. 
heat tolerance (Byrne et al., 2016). However, it is worth considering whether heat tolerance should be included in the breeding goal to minimize $\mathrm{G} \times \mathrm{E}$ and thereby improve resilience.

In this study, we considered only the magnitude of re-ranking of genotypes across climate covariate (THI) with respect to production traits. It is also important to consider other traits, because sire selection indices in Australia are designed to include different aspects of farm profitability, including production, fertility, health, functional, and type as well as efficiency traits (Byrne et al., 2016). Selecting for resilience would be advantageous if the desire is to simultaneously achieve an optimal level of ES for multiple traits. Therefore, it would also be useful to quantify ES in other traits, such as fertility, health, functional, and efficiency traits. In this regard, $\mathrm{G} \times \mathrm{E}$ for fertility traits in relation to heat stress merits investigation and will be a subject of a subsequent study.

\section{CONCLUSIONS}

Our results demonstrate that $\mathrm{G} \times \mathrm{E}$ exists at extreme heat stress conditions (genetic correlations for all the milk traits were $\geq 0.80$ ) but currently, the extent of re-ranking for most of the sires may not justify separate genetic evaluations for high heat stress environments. In addition, we observed lower correlation estimates for first-parity milk tests from recent years (i.e., 2009 and 2017) than for milk tests from earlier years (i.e., 2003 and 2008), which suggests that the level of $G \times E$ is increasing in the study population and should be regularly monitored, especially considering the anticipated increase in climate changes. The reaction norms for sire

2003 to 20082009 to 2017
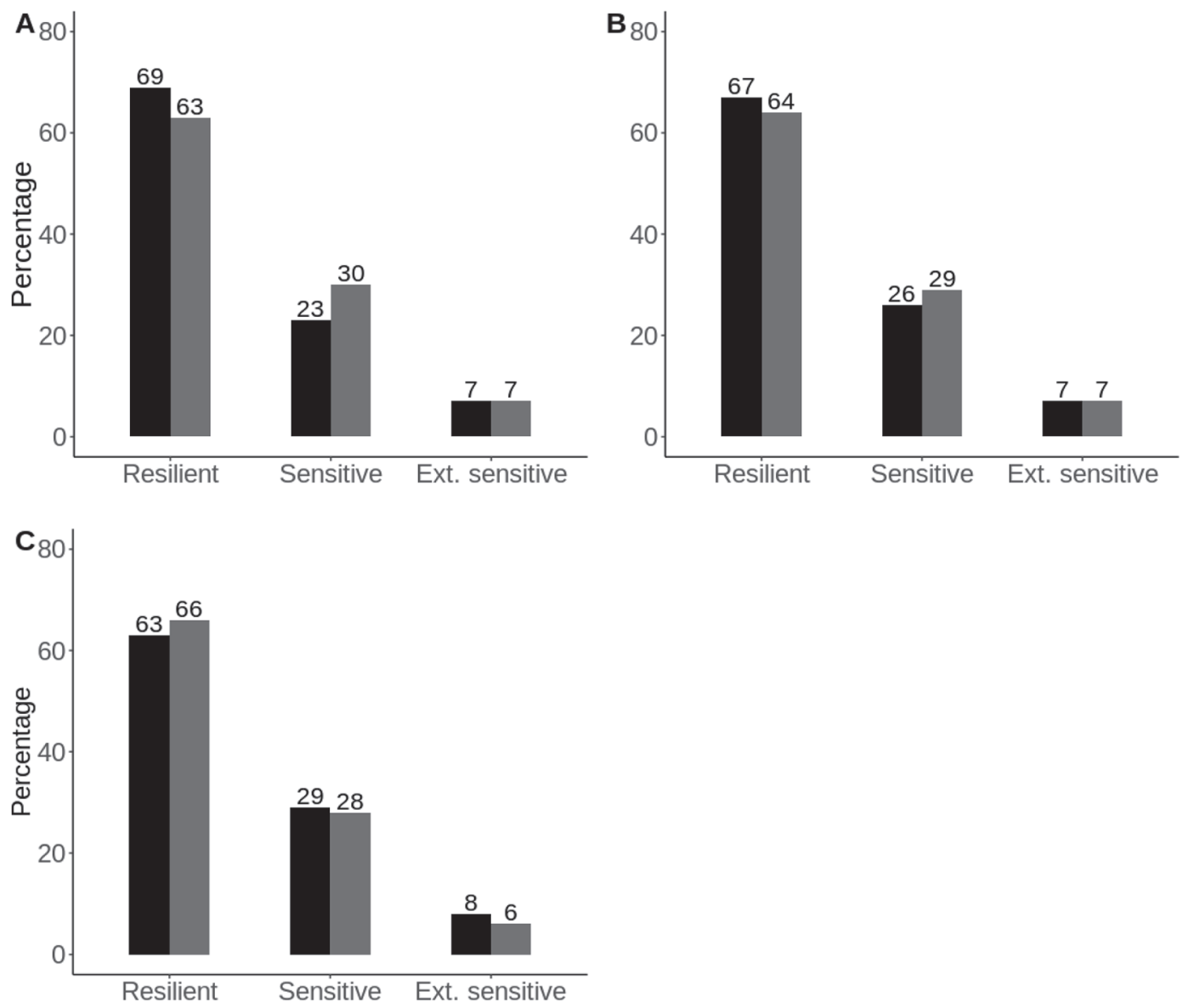

Figure 8. Proportion of resilient, heat sensitive, and extremely (ext.) sensitive sires for milk (A), protein (B), and fat yields (C) of firstparity milk tests from 2003 to 2008 and 2009 to 2017. Sires are grouped based on absolute values of the slope $(S)$ of the reaction norms: $\left|S_{i}\right|<\sigma_{S}$, resilient sires; $\sigma_{S} \leq\left|S_{i}\right|<2 \sigma_{S}$, sensitive sires, and $\left|S_{i}\right| \geq 2 \sigma_{S}$, extremely sensitive sires. Values on the tops of the bars are actual percentages. 
EBV along the trajectory of THI indicates that genetic variations exist, which can be used to select animals that perform optimally in different environments.

\section{ACKNOWLEDGMENTS}

This study was supported by DairyBio (Melbourne, Australia), funded by Dairy Australia (Melbourne, Australia), the Gardiner Foundation (Melbourne, Australia), and Agriculture Victoria (Melbourne, Australia). The first author acknowledges a PhD scholarship from La Trobe University (Melbourne, Australia) and DairyBio. Special thanks to all farmers involved in the study and to DataGene Ltd. (Melbourne, Australia), for providing the data. The authors have not stated any conflicts of interest.

\section{REFERENCES}

Aguilar, I., I. Misztal, and S. Tsuruta. 2009. Genetic components of heat stress for dairy cattle with multiple lactations. J. Dairy Sci. 92:5702-5711. https://doi.org/10.3168/jds.2008-1928.

Berghof, T. V. L., M. Poppe, and H. A. Mulder. 2019. Opportunities to improve resilience in animal breeding programs. Front. Genet. 9:692. https://doi.org/10.3389/fgene.2018.00692.

Bernabucci, U., S. Biffani, L. Buggiotti, A. Vitali, N. Lacetera, and A. Nardone. 2014. The effects of heat stress in Italian Holstein dairy cattle. J. Dairy Sci. 97:471-486. https://doi.org/10.3168/jds.2013 $-6611$.

Bohlouli, M., S. Alijani, S. Naderi, T. Yin, and S. König. 2019. Prediction accuracies and genetic parameters for test-day traits from genomic and pedigree-based random regression models with or without heat stress interactions. J. Dairy Sci. 102:488-502. https:/ /doi.org/10.3168/jds.2018-15329.

Bohlouli, M., J. Shodja, S. Alijani, and A. Eghbal. 2013. The relationship between temperature-humidity index and test-day milk yield of Iranian Holstein dairy cattle using random regression model. Livest. Sci. 157:414-420. https://doi.org/10.1016/j.livsci.2013.09 .005 .

Bohmanova, J., I. Misztal, S. Tsuruta, H. Norman, and T. Lawlor. 2005. National genetic evaluation of milk yield for heat tolerance of United States Holsteins. Interbull Bull. 160.

Brügemann, K., E. Gernand, U. Von Borstel, and S. König. 2011. Genetic analyses of protein yield in dairy cows applying random regression models with time-dependent and temperature $\times$ humidity-dependent covariates. J. Dairy Sci. 94:4129-4139. https://doi .org/10.3168/jds.2010-4063.

Bryant, J., N. López-Villalobos, J. Pryce, C. Holmes, and D. Johnson. 2006. Reaction norms used to quantify the responses of New Zealand dairy cattle of mixed breeds to nutritional environment. N. Z. J. Agric. Res. 49:371-381. https://doi.org/10.1080/00288233 .2006 .9513727 .

Byrne, T. J., B. F. S. Santos, P. R. Amer, D. Martin-Collado, J. E. Pryce, and M. Axford. 2016. New breeding objectives and selection indices for the Australian dairy industry. J. Dairy Sci. 99:81468167. https://doi.org/10.3168/jds.2015-10747.

Carabaño, M. J., K. Bachagha, M. Ramón, and C. Díaz. 2014. Modeling heat stress effect on Holstein cows under hot and dry conditions: Selection tools. J. Dairy Sci. 97:7889-7904. https://doi.org/ 10.3168/jds.2014-8023.

Carabaño, M. J., M. Ramón, C. Díaz, A. Molina, M. D. Pérez-Guzmán, and J. M. Serradilla. 2017. Breeding and genetics symposium: breeding for resilience to heat stress effects in dairy ruminants. A comprehensive review. J. Anim. Sci. 95:1813-1826. https://doi .org/10.2527/jas2016.1114.
Colditz, I. G., and B. C. Hine. 2016. Resilience in farm animals: Biology, management, breeding and implications for animal welfare. Anim. Prod. Sci. 56:1961-1983. https://doi.org/10.1071/AN15297.

CSIRO and BoM. 2018. State of the climate 2018, CSIRO. Accessed Aug. 24, 2018. https://www.csiro.au /media/OnA/Files/State-of -the-Climate-2018-CSIRO-BOM-Dec2018.pdf.

Dairy Australia. 2016. Australian dairy industry in focus - 2016. Accessed Jul. 12, 2018. https://www.dairyaustralia.com.au/ -/media/dairyaustralia/documents/about-dairy-australia/key -publications/2016-in-focus.pdf.

DataGene. 2016. Australian dairy herd improvement report. Accessed Jun. 17, 2018. https://datagene.com.au/sites/default/files/Upload \%20Files/Australian\%20Dairy\%20Herd\%20Improvement\%20\%20 Report\%202016.pdf.

de Jong, G., and P. Bijma. 2002. Selection and phenotypic plasticity in evolutionary biology and animal breeding. Livest. Prod. Sci. 78:195-214. https://doi.org/10.1016/S0301-6226(02)00096-9.

Falconer, D. S., and T. F. C. MacKay Longman. 1996. Introduction to Quantitative Genetics. 4th ed. D. S. Falconer and T. F. C. Mackay Longman, ed. Pearson Education Limited, Essex, UK.

Fischer, T. M., A. R. Gilmour, and J. H. J. van der Werf. 2004. Computing approximate standard errors for genetic parameters derived from random regression models fitted by average information REML. Genet. Sel. Evol. 36:363. https://doi.org/10.1186/ 1297-9686-36-3-363.

Friggens, N. C., F. Blanc, D. P. Berry, and L. Puillet. 2017. Deciphering animal robustness. A synthesis to facilitate its use in livestock breeding and management. Animal 11:2237-2251. https://doi.org/ 10.1017/S175173111700088X.

Gerber, P. J., H. Steinfeld, B. Henderson, A. Mottet, C. Opio, J. Dijkman, A. Falcucci, and G. Tempio. 2013. Tackling climate change through livestock: A global assessment of emissions and mitigation opportunities. Food and Agriculture Organization of the United Nations (FAO), Rome, Italy.

Gilmour, A., B. Gogel, B. Cullis, S. Welham, and R. Thompson. 2015. ASReml User Guide Release 4.1 Structural Specification. VSN International Ltd., Hemel Hempstead, UK.

Haile-Mariam, M., M. Carrick, and M. Goddard. 2008. Genotype by environment interaction for fertility, survival, and milk production traits in Australian dairy cattle. J. Dairy Sci. 91:4840-4853. https: //doi.org/10.3168/jds.2008-1084.

Hammami, H., J. Vandenplas, M.-L. Vanrobays, B. Rekik, C. Bastin, and N. Gengler. 2015. Genetic analysis of heat stress effects on yield traits, udder health, and fatty acids of Walloon Holstein cows. J. Dairy Sci. 98:4956-4968. https://doi.org/10.3168/jds.2014 -9148 .

Hayes, B. J., M. Carrick, P. Bowman, and M. E. Goddard. 2003. Genotype $\times$ environment interaction for milk production of daughters of Australian dairy sires from test-day records. J. Dairy Sci. 86:3736-3744. https://doi.org/10.3168/jds.S0022-0302(03)73980 -0 .

Kolmodin, R., E. Strandberg, P. Madsen, J. Jensen, and H. Jorjani. 2002. Genotype by environment interaction in Nordic dairy cattle studied using reaction norms. Acta Agric. Scand. A Anim. Sci 52:11-24. https://doi.org/10.1080/09064700252806380.

Mattar, M., L. Silva, M. Alencar, and F. Cardoso. 2011. Genotype × environment interaction for long-yearling weight in Canchim cattle quantified by reaction norm analysis. J. Anim. Sci. 89:2349-2355. https://doi.org/10.2527/jas.2010-3770.

Misztal, I., T. Strabel, J. Jamrozik, E. A. Mäntysaari, and T. H. E. Meuwissen. 2000. Strategies for estimating the parameters needed for different test-day models. J. Dairy Sci. 83:1125-1134. https:// doi.org/10.3168/jds.S0022-0302(00)74978-2.

Mulder, H. A. 2016. Genomic selection improves response to selection in resilience by exploiting genotype by environment interactions. Front. Genet. 7. https://doi.org/10.3389/fgene.2016.00178.

Nguyen, T. T., P. J. Bowman, M. Haile-Mariam, G. J. Nieuwhof, B. J. Hayes, and J. E. Pryce. 2017. Implementation of a breeding value for heat tolerance in Australian dairy cattle. J. Dairy Sci. 100:7362-7367. https://doi.org/10.3168/jds.2017-12898. 
Nguyen, T. T., P. J. Bowman, M. Haile-Mariam, J. E. Pryce, and B. J. Hayes. 2016. Genomic selection for tolerance to heat stress in Australian dairy cattle. J. Dairy Sci. 99:2849-2862. https://doi .org/10.3168/jds.2015-9685.

Polsky, L., and M. A. von Keyserlingk. 2017. Invited review: Effects of heat stress on dairy cattle welfare. J. Dairy Sci. 100:8645-8657. https://doi.org/10.3168/jds.2017-12651.

Pryce, J. E., T. T. T. Nguyen, M. Axford, G. Nieuwhof, and M. Shaffer. 2018. Symposium review: Building a better cow-The Australian experience and future perspectives. J. Dairy Sci. 101:37023713. https://doi.org/10.3168/jds.2017-13377.

Ravagnolo, O., and I. Misztal. 2000. Genetic component of heat stress in dairy cattle, parameter estimation. J. Dairy Sci. 83:2126-2130. https://doi.org/10.3168/jds.S0022-0302(00)75095-8.

Ravagnolo, O., I. Misztal, and G. Hoogenboom. 2000. Genetic component of heat stress in dairy cattle, development of heat index function. J. Dairy Sci. 83:2120-2125. https://doi.org/10.3168/jds .S0022-0302(00)75094-6.

Renaudeau, D., A. Collin, S. Yahav, V. De Basilio, J. Gourdine, and R. Collier. 2012. Adaptation to hot climate and strategies to alleviate heat stress in livestock production. Animal 6:707-728. https://doi .org/10.1017/S1751731111002448.

Santana, M. L. Jr., R. J. Pereira, A. B. Bignardi, A. E. Vercesi Filho, A. Menendez-Buxadera, and L. El Faro. 2015. Detrimental effect of selection for milk yield on genetic tolerance to heat stress in purebred Zebu cattle: genetic parameters and trends. J. Dairy Sci. 98:9035-9043. https://doi.org/10.3168/jds.2015-9817.

Strabel, T., J. Szyda, E. Ptak, and J. Jamrozik. 2005. Comparison of random regression test-day models for Polish Black and White cattle. J. Dairy Sci. 88:3688-3699. https://doi.org/10.3168/jds .S0022-0302(05)73055-1.

Su, G., M. S. Lund, and D. Sorensen. 2007. Selection for litter size at day five to improve litter size at weaning and piglet survival rate1. J. Anim. Sci. 85:1385-1392. https://doi.org/10.2527/jas.2006-631.

West, J. W. 2003. Effects of heat-stress on production in dairy cattle. J. Dairy Sci. 86:2131-2144. https://doi.org/10.3168/jds.S0022 -0302(03)73803-X.

Yousef, M. K. 1985. Stress Physiology in Livestock. Volume I. Basic Principles. CRC Press, Boca Raton, FL.

\section{ORCIDS}

E. K. Cheruiyot @ https://orcid.org/0000-0002-6403-7967

M. Haile-Mariam () https://orcid.org/0000-0001-5476-7475

J. E. Pryce $\odot$ https://orcid.org/0000-0002-1397-1282 